\title{
A Fractographic Study of Bending/Torsion Fatigue Failure in Metallic Materials with Protective Surface Layers
}

\author{
Karel Slámečka, ${ }^{1,2}$ Petr Šesták, ${ }^{1,2}$ Tomáš Vojtek, ${ }^{1}$ Marta Kianicová, ${ }^{3}$ Jana Horníková, ${ }^{1,2}$ \\ Pavel Šandera, ${ }^{1,2}$ and Jaroslav Pokluda ${ }^{1,2}$ \\ ${ }^{1}$ Central European Institute of Technology, Brno University of Technology, Technická 3058/10, 61600 Brno, Czech Republic \\ ${ }^{2}$ Faculty of Mechanical Engineering, Brno University of Technology, Technická 2896/2, 61669 Brno, Czech Republic \\ ${ }^{3}$ Faculty of Industrial Technology, Alexander Dubček University in Trenčín, Ivana Krasku 491/30, 02001 Púchov, Slovakia
}

Correspondence should be addressed to Karel Slámečka; karel.slamecka@ceitec.vutbr.cz

Received 9 March 2016; Revised 10 May 2016; Accepted 18 May 2016

Academic Editor: Gianfranco Palumbo

Copyright (C) 2016 Karel Slámečka et al. This is an open access article distributed under the Creative Commons Attribution License, which permits unrestricted use, distribution, and reproduction in any medium, provided the original work is properly cited.

\begin{abstract}
Results are given of a fractographic study of biaxial in-phase bending/torsion fatigue fractures in specimens made of nitrided steel and nickel-based superalloy with protective coatings (diffusion coatings and plasma-sprayed thermal barrier coatings). Fracture surfaces were examined by optical and scanning electron microscopes while stereophotogrammetry and optical profilometry were employed to obtain 3D surface data of selected fracture surface regions. The studied materials exhibited a wide range of fracture mechanisms depending on the microstructure and applied mechanical loading.
\end{abstract}

\section{Introduction}

Surface engineering is used for enhancing the functional properties of variety of engineering parts. In aircraft, automotive, machinery, and power generation applications, an improved resistance to wear, fatigue, and corrosion is needed, which is often achieved via thermochemical treatment or by surface painting or coating. Whether the component is nitrided, carburized, chromized, and so forth or if it is prepared with a protective coating, each of the methods modifies the surface layer and introduces a gradient or a sharp change of material properties near the surface that adds to the complexity of the failure process, particularly when subjected to complex cyclic loading.

A common example is the rotational structural parts that operate mostly under combined axial and torsional loading $[1,2]$. When studying in-service failure of such a component, fractography (i.e., the study of fracture surface which is deemed to be a failure process gauge for failure mode analysis [3-5]) is useful to assess the relative importance of each loading regime. In this paper, room-temperature bending/ torsion fatigue fractures in nitrided steel and in nickel-based superalloy with aluminide diffusion and thermal barrier high-temperature coatings, reported on earlier in [6-9], are discussed based on additional microscopic observations of fracture surfaces and 3D topographical data of selected surface regions.

\section{Experimental}

\subsection{Studied Materials}

2.1.1. Nitrided Steel. The substrate material was a highstrength low-alloy Cr-Al-Mo nitriding steel, which was annealed $\left(920^{\circ} \mathrm{C}, 25 \mathrm{~min}\right.$, air), quenched $\left(930^{\circ} \mathrm{C}, 25 \mathrm{~min}\right.$, oil), and tempered $\left(650^{\circ} \mathrm{C}, 25 \mathrm{~min}\right.$, air), prior to micropulse plasma nitriding (cleaning: $510^{\circ} \mathrm{C}, 30 \mathrm{~min}$; nitriding: $515^{\circ} \mathrm{C}$, $8 \mathrm{~h}$ ) performed in a protective argon atmosphere. The microstructurally distinguishable nitride layer with a thickness of $\sim 0.2 \mathrm{~mm}$ introduced high compressive residual stresses near the surface (approximately $-800 \mathrm{MPa}$ in maximum) and small balancing tensile stresses (50 MPa in maximum) in the core $(h>0.7 \mathrm{~mm})$ that are required to maintain stress equilibrium [6]. 
2.1.2. Nickel-Based Superalloy with High-Temperature Coatings. The substrate material was cast Inconel 713LC nickelbased superalloy with the average grain size of $\sim 2.3 \mathrm{~mm}$ (diffusion coatings (DCs)) and $\sim 1 \mathrm{~mm}$ (thermal barrier coatings (TBCs)). Diffusion coatings consist of aluminide and Crmodified aluminides and were deposited by the out-of-pack method $\left(1050^{\circ} \mathrm{C}, 5 \mathrm{~h}\right)$. After diffusion annealing $\left(950^{\circ} \mathrm{C}, 5 \mathrm{~h}\right.$, protective atmosphere), both aluminide DCs had the total thickness of $\sim 80 \mu \mathrm{m}$ and consisted of two distinct sublayers (an outer layer and an interdiffusion zone) with more or less well-defined interface between them [8]. Thermal barrier coatings consisted of a CoNiCrAlY bond coat and a ceramic $\mathrm{ZrO}_{2}-\mathrm{Y}_{2} \mathrm{O}_{3}$ (yttria stabilized zirconia (YSZ)) top coat. Both CoNiCrAlY and YSZ coatings were prepared by atmospheric plasma spraying from commercially available powders AMDRY 995 (Al: 8\%, Y: 0.5\%, Cr: 21\%, Ni: 32\%, and Co: balance) and GTV 40.23.1 ( $\mathrm{Y}_{2} \mathrm{O}_{3}: 8 \%, \mathrm{ZrO}_{2}$ : balance). The thicknesses of the bond coat and the top coat were $0.21 \mathrm{~mm}$ and $0.18 \mathrm{~mm}$, respectively. Several specimens were oxidized in air $\left(1050^{\circ} \mathrm{C}\right.$ for $\left.200 \mathrm{~h}\right)$ producing a thin $(\sim 5 \mu \mathrm{m})$ layer of high-temperature oxides and other compounds at the metallic/ceramic interface (the so-called TGO layer) that is progressively formed in service [9]. Although both DCs and TBCs are designed to provide protection against hightemperature oxidation and hot corrosion, failure frequently occurs at low temperatures following the shutdown of the engine [10].

2.2. Fatigue Experiments and Fractography. Fatigue experiments were conducted on smooth cylindrical specimens by means of the testing stand MZGS-200 constructed at the Opole University of Technology, Opole, Poland (see [11] for details). Symmetric bending, symmetric torsion, and their synchronous in-phase combinations were applied with a frequency $f \sim 30 \mathrm{~Hz}$ at room temperature. The bending stress was the highest at the two opposite specimen side surfaces while the torsion stress was radially symmetric and constant along the circumference. Stresses were maximal at the surface and linearly decreased towards the centre. For simplicity, the loading regime is described in terms of the loading ratio $Z$ defined here as

$$
Z=\frac{\sqrt{3} \tau_{a}}{\sigma_{a}+\sqrt{3} \tau_{a}},
$$

where $\sigma_{a}$ is the bending amplitude, $\tau_{a}$ is the torsion amplitude, and the weighting factor of $\sqrt{3}$ derives from the von Mises yield criterion. The loading ratio $Z$ is zero for pure bending, equals one for pure torsion, and is between zero and one for combined bending and torsion. Definition (1) reflects the contributions of both loading components to the fatigue failure at $Z=1 / 2$ better than the simpler formula without the weighting factor. Various tests were conducted at $Z=0$, $Z \sim 0.4, Z \sim 0.6, Z \sim 0.8$, and $Z \sim 1$. After failure, fracture surfaces were examined in optical and scanning electron microscopes (SEM). 3D topographical data of selected surface regions were extracted either by means of SEM stereophotogrammetry (e.g., [12]) or via optical profilometry in order to determine the orientation of the fracture plane.

\section{Fractographic Examination and Discussion}

3.1. Nitrided Steel Specimens. The nitrided steel specimens were tested in the high cycle fatigue domain (fatigue life, $N_{f}$, was from $2.0 \times 10^{5}$ to $6.1 \times 10^{6}$ cycles) and they all failed by an internal "fish-eye" type of fracture because the applied loading was too low to damage the nitride layer and cause the failure from the surface. The cracks always initiated at nonmetallic inclusions in the core material and formed a nearly elliptical internal fish-eye crack [6] (Figure 1). Failure sequence consisted of (i) decohesion of the inclusionmatrix interface (which, most likely, constitutes a major part of the total life [7]), (ii) growth of the internal fisheye crack, (iii) sudden breakage through the low-toughness nitride layer, (iv) fast, atmosphere-assisted crack growth [13], and (v) a final quasistatic fracture of the intact middle cross section. This is demonstrated in Figure 1 showing the fracture in the specimen tested under combined bending-torsion loading where two fish-eye cracks initiated at the opposite sites experiencing the maximum bending stress. The cracks initiated in a depth of $0.68 \mathrm{~mm}$ at an inclusion with effective diameter of $\sim 20 \mu \mathrm{m}$ (Figure 1(a)) and in a depth of $0.58 \mathrm{~mm}$ at an inclusion with diameter of $\sim 15 \mu \mathrm{m}$ (Figure 1(b)).

A general tendency of the fish-eye cracks was to grow in opening mode I as revealed by the orientation of the crack plane that changed from being perpendicular to the specimen's longitudinal axis for pure bending to a tangential inclination (along the circumference) of $\sim 45^{\circ}$ for torsion. Figure 2 shows arbitrarily rotated 3D images of the fish-eye cracks from Figures 1(a) and 1(b). The inclination angle of the fracture surfaces was determined from the orientations of the intersecting profiles marked in Figure 2. In this case, the radial inclination (toward the centre) $\alpha_{r}$ was negligible and the tangential inclination $\alpha_{t}$ was $\sim 30^{\circ}$ (Figure 3 ) in correspondence with the applied torsion-dominant loading regime $(Z=0.63)$.

3.2. Diffusion Coatings. In aluminide and Cr-modified aluminide diffusion coatings, the cracks initiated either at the free surface or at both the surface and the secondary-phase particles within the upper part of the diffusion zone, if there were sufficiently high normal stresses at the particle/matrix interface. This resulted in the fatigue performance being sensitive to the loading regime and the stress level (uncoated specimens outperformed the coated ones in the low cycle fatigue region when subjected to bending and combined bending-torsion loading) [8]. The cracks that initiated on the secondary-phase particles inside the coating gradually interconnected and propagated towards the free surface as well as into the specimen bulk as shown in Figure 4 for specimen tested under combined bending-torsion loading. The white arrows in this figure indicate the local crack growth direction, as deduced from the convex shape of imprints of subsequent crack front positions (fatigue striations). This is caused by slower crack propagation at the grain boundaries that inhibit the crack opening and blunting due to the limited dislocation emission. It leads to the convex shape of striations which bow out in the direction of crack propagation [14]. Numerous secondary-phase particles are clearly visible in both the outer 


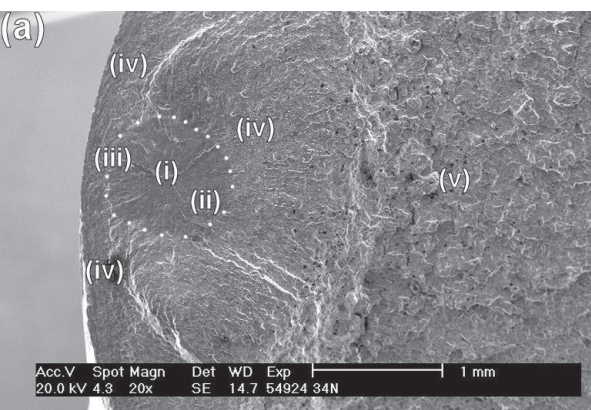

(a)

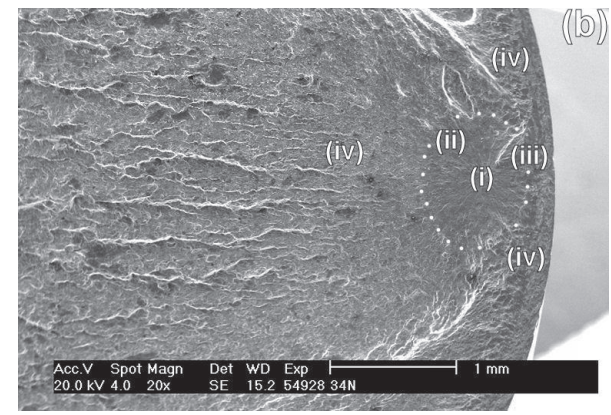

(b)

FIGURE 1: Initiation sites in nitrided steel specimen subjected to combined bending-torsion loading $\left(Z=0.63, N_{f}=2.0 \times 10^{5}\right.$ cycles $)$ with the failure sequence phases marked in images.

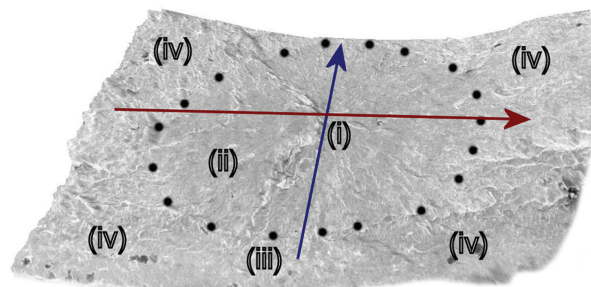

(a)

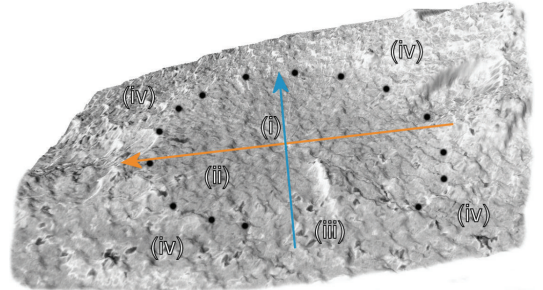

(b)

FIGURE 2: 3D images of the fish-eye cracks from Figure 1.

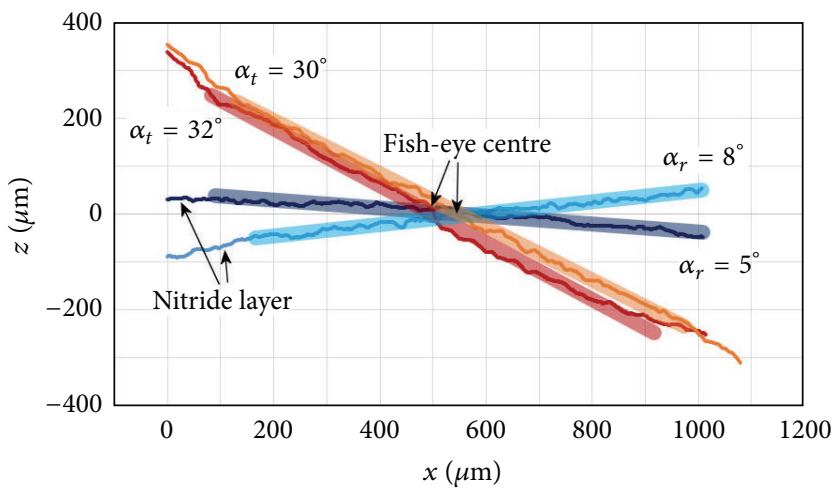

FIGURE 3: Profiles marked in Figure 2 with highlighted fish-eye segments.

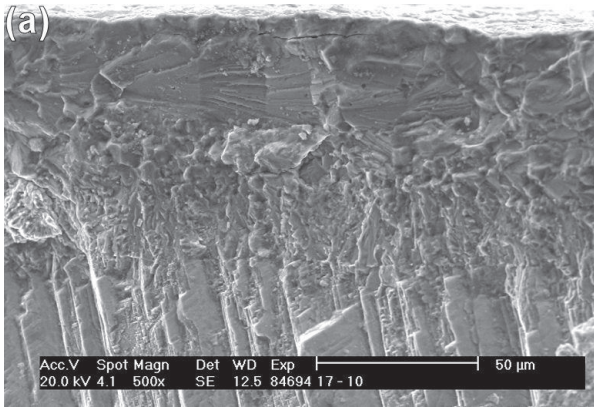

(a)

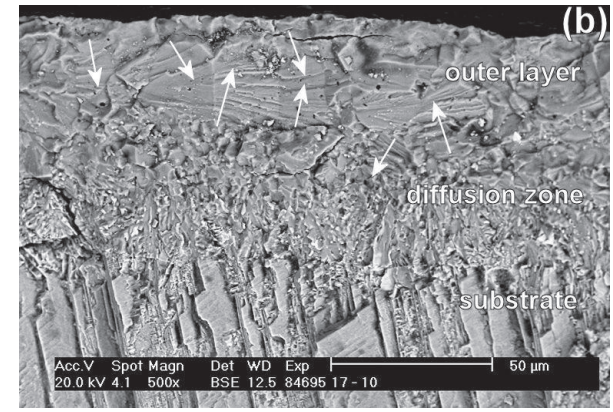

(b)

FIGURE 4: Initiation site in specimen with aluminide DC subjected to combined bending-torsion loading $\left(Z=0.58, N_{f}=6.0 \times 10^{4}\right.$ cycles $)$ using (a) secondary (SE) and (b) back-scattered electrons (BSE). 


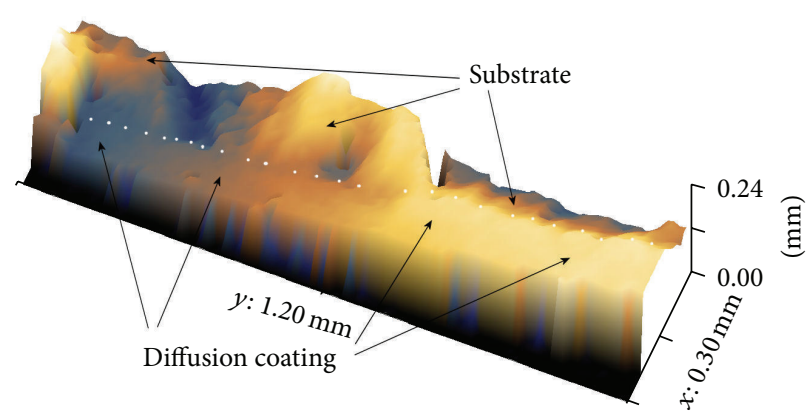

(a)

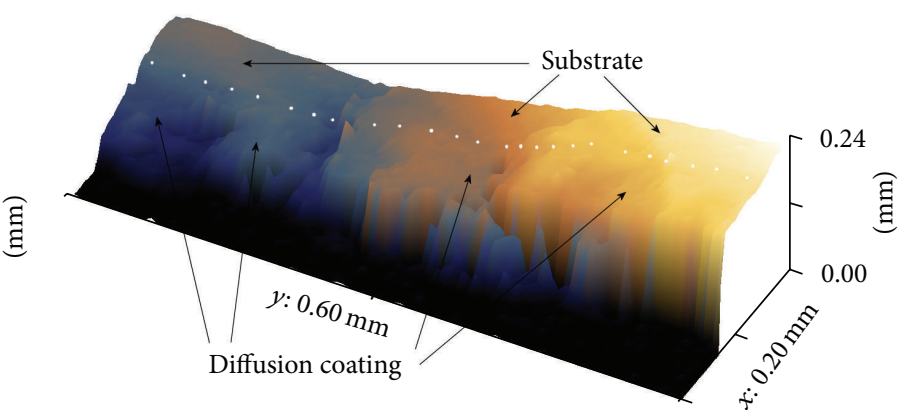

(b)

Figure 5: $3 \mathrm{D}$ view of initiation sites in specimens subjected to (a) bending ( $Z=0, N_{f}=6.3 \times 10^{3}$ cycles) and (b) torsion loading ( $Z=1$, $N_{f}=7.0 \times 10^{2}$ cycles).

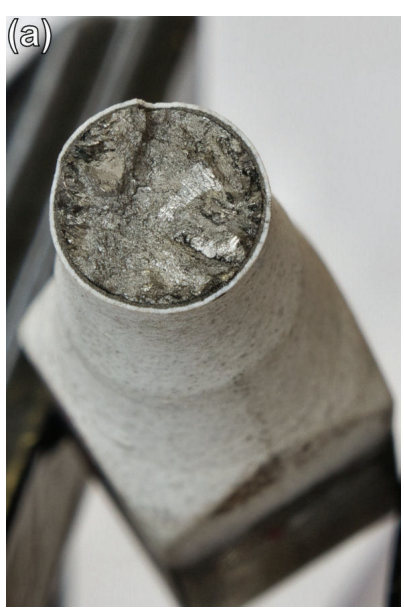

(a)

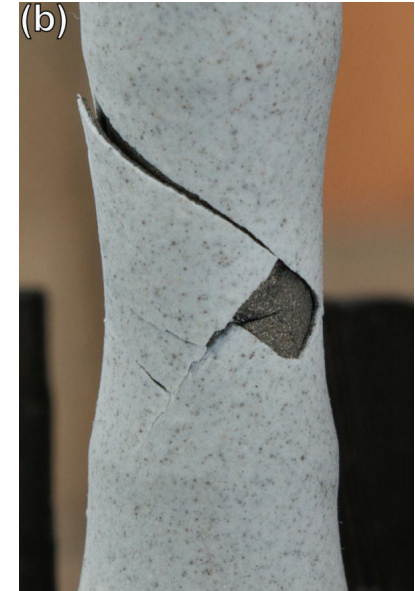

(b)

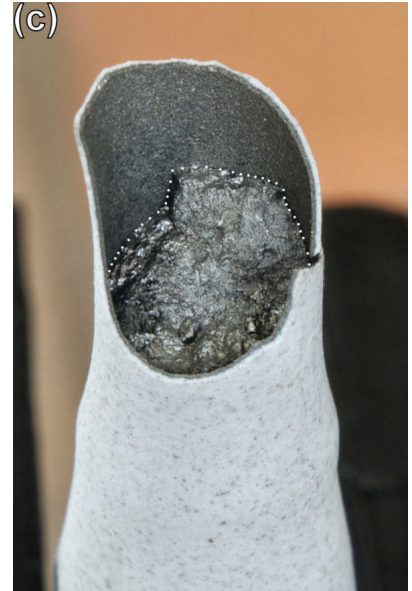

(c)

FIgurE 6: Macroimages of specimens with TBCs subjected to (a) pure bending ( $Z=0, N_{f}=1.3 \times 10^{5}$ cycles), (b) combined bending-torsion $\left(Z=0.64, N_{f}=6.6 \times 10^{4}\right.$ cycles $)$, and (c) pure torsion loading $\left(Z=1, N_{f}=2.1 \times 10^{5}\right.$ cycles $)$.

layer and the diffusion zone, especially in the BSE imaging mode (Figure 4(b)). Figure 5 shows the initiation sites in specimens tested under pure bending and torsion in the low cycle fatigue region. In general, high applied loading caused cracking and partial coating spallation, particularly under regimes involving torsion (short delamination cracks are also seen in Figure 4).

3.3. Thermal Barrier Coatings. In this case, cracks likely always initiated on the preexisting defects within the ceramic top coat at or near the surface. As for the diffusion coatings, the crack path through the substrate was torturous and highly irregular owing to a complex microstructure, high roughness-induced crack closure, and the multiple active crack growth micromechanisms, all of which are typical for nickel-based superalloys [15]. The torsion component was found to promote propagation of inclined surface cracks (generally $\sim 45^{\circ}$ with respect to the specimen longitudinal axis for torsion-dominant loading regimes) and extensive delamination of the coating from the substrate (Figure 6). The reason for such large-scale delamination is shearing of a mechanically bonded layer that induces high normal stresses at geometrically irregular coating/substrate interface along the specimen. Delamination occurred also under pure bending loading but was limited to the two opposite specimen sides that experienced maximal bending stress (Figure 7) [9].

From the mechanical point of view, the bond-coat/substrate interface was the weakest part of the studied system, as was also observed earlier for the similar TBC systems $[16,17]$. The top-coat/bond-coat interface, on the other hand, presented a rather weak barrier at which the crack front locally somewhat deviated if the applied stresses were low or if the thermally grown oxide (TGO) layer was present (Figure 8(b)). In this case, a complex fracture behaviour of the TGO layer was observed including the cracks through the thickness and along its interfaces [9]. Interestingly, this had no impact on the fatigue life of oxidized specimens which was comparable to that of as-sprayed samples. 


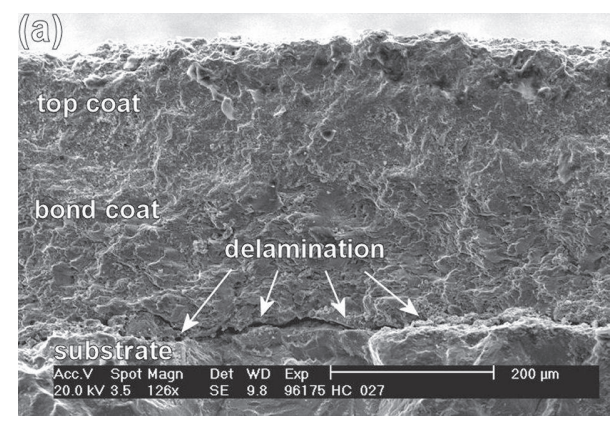

(a)

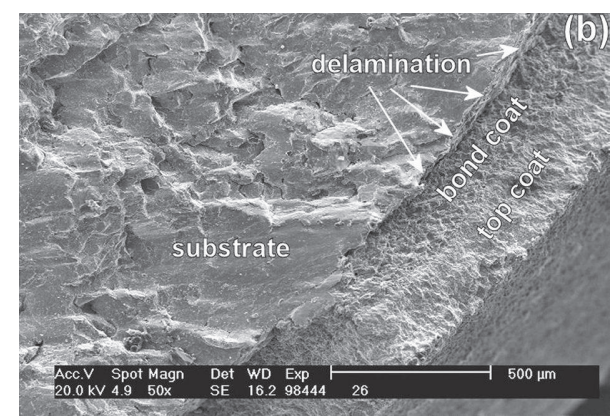

(b)

FIGURE 7: Initiation sites in specimens with thermal barrier coatings subjected to (a) bending $\left(Z=0, N_{f}=2.7 \times 10^{4}\right.$ cycles) and (b) combined bending-torsion $\left(Z=0.64, N_{f}=4.2 \times 10^{4}\right.$ cycles) loading.

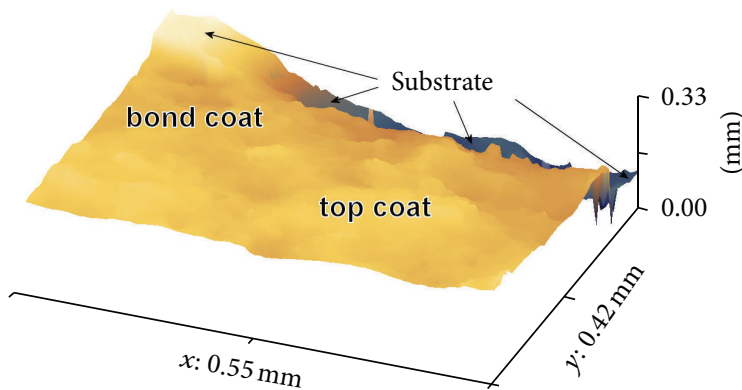

(a)

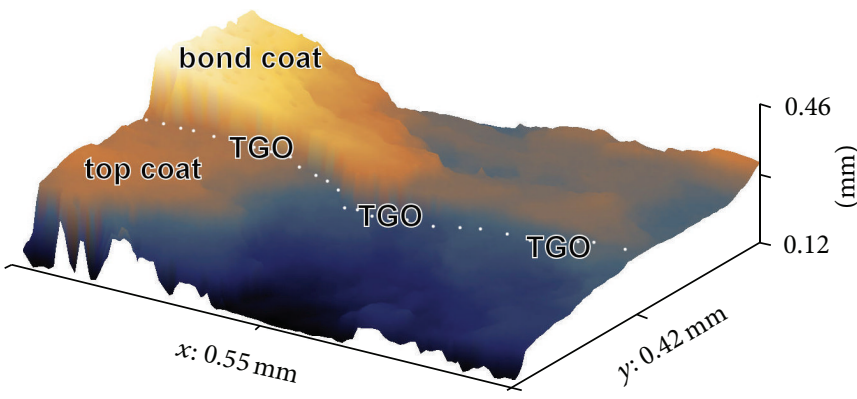

(b)

FIGURE 8: 3D view of initiation sites in specimens with TBCs subjected to pure bending: (a) as-sprayed specimen $\left(N_{f}=1.3 \times 10^{5}\right.$ cycles $)$ and (b) oxidized specimen with $\sim 5 \mu \mathrm{m}$ thick TGO layer between the bond coat and the top coat $\left(N_{f}=8.6 \times 10^{5}\right.$ cycles $)$.

\section{Conclusion}

As diverse as they were, the studied materials exhibited a wide range of fracture mechanisms in response to the applied bending/torsion mechanical loading. The nitrided steel specimens, because of the hard nitride case and high near-surface compressive residual stresses, failed due to a fish-eye type of fracture that originated at internal nonmetallic inclusions and tended to grow under opening mode I, regardless of the loading regime. In diffusion coatings, cracks were initiated both at the free surface and on secondary-phase particles, especially when there were high normal stresses available at the particle/matrix interface (i.e., high loading, bendingdominant regimes). In the thermal barrier coatings, cracks grew from preexisting defects in the ceramic top coat. Largescale delamination of the coating from the substrate was observed for loading modes that involved torsion as a result of high interfacial normal stresses induced by shearing of geometrically irregular mechanically bonded layers.

\section{Competing Interests}

The authors declare that they have no competing interests.

\section{Acknowledgments}

This research was carried out under the project CEITEC 2020 (LQ1601) with financial support from the Ministry of Education, Youth and Sports of the Czech Republic under National Sustainability Programme II and the project VEGA 1/0385/14 with financial support from the Ministry of Education, Science, Research and Sport of the Slovak Republic.

\section{References}

[1] C. Karaagac and M. E. Toygar, "Fracture and fatigue analysis of an agitator shaft with a circumferential notch," Engineering Fracture Mechanics, vol. 73, no. 14, pp. 2034-2052, 2006.

[2] P. Davoli, A. Bernasconi, M. Filippini, S. Foletti, and I. V. Papadopoulos, "Independence of the torsional fatigue limit upon a mean shear stress," International Journal of Fatigue, vol. 25, no. 6, pp. 471-480, 2003.

[3] K. Mills, J. R. Davis, J. D. Destefani et al., "History fractography," in Metals Handbook, vol. 12, pp. 1-9, ASM International, Metals Park, Ohio, USA, 1992.

[4] A. D. Vasilev, "Fractography and failure analysis of materials studied by SEM," in Microscopy and Analysis, vol. 66, pp. 23-26, 1998. 
[5] R. J. Parrington, "Fractography of metals and plastics," Practical Failure Analysis, vol. 2, no. 5, pp. 16-46, 2002.

[6] K. Slámečka, J. Pokluda, M. Kianicová, Š. Major, and I. Dvořák, "Quantitative fractography of fish-eye crack formation under bending-torsion fatigue," International Journal of Fatigue, vol. 32, no. 6, pp. 921-928, 2010.

[7] K. Slámečka, J. Pokluda, and M. Kianicová, "Fractographicallyaided analysis of fish-eye crack growth in nitrided steel," Journal of Theoretical and Applied Mechanics, vol. 51, no. 2, pp. 439-446, 2013.

[8] K. Slámečka, J. Pokluda, M. Kianicová, J. Horníková, and K. Obrtlík, "Fatigue life of cast Inconel 713LC with/without protective diffusion coating under bending, torsion and their combination," Engineering Fracture Mechanics, vol. 110, pp. 459467, 2013.

[9] K. Slámečka, L. Čelko, P. Skalka et al., "Bending fatigue failure of atmospheric-plasma-sprayed CoNiCrAlY + YSZ thermal barrier coatings," International Journal of Fatigue, vol. 70, pp. 186-195, 2015.

[10] N. A. Fleck, A. C. F. Cocks, and S. Lampenscherf, "Thermal shock resistance of air plasma sprayed thermal barrier coatings," Journal of the European Ceramic Society, vol. 34, no. 11, pp. 26872694, 2014.

[11] E. Macha, L. Kasprzyczak, and G. Mirek, "Digital control systems based on Matlab/Simulink software for strength machines," Journal of Vibration and Control, vol. 18, no. 2, pp. 201-208, 2012.

[12] J. Stampfl, S. Scherer, M. Gruber, and O. Kolednik, "Reconstruction of surface topographies by scanning electron microscopy for application in fracture research," Applied Physics A: Materials Science and Processing, vol. 63, no. 4, pp. 341-346, 1996.

[13] I. Dvořák and J. Hanák, "Fatigue fracture initiation and propagation in nitride parts," in Proceedings of the 7th International Fatigue Congress (Fatigue '99), X. R. Wu, Ed., pp. 481-486, Beijing, China, June 1999.

[14] V. Kerlins, "Modes of fracture," in ASM Handbook, R. L. Stedfeld, J. R. Davis, P. Allen et al., Eds., vol. 12 of Fractography, p. 16, ASM International, Novelty, Ohio, USA, 1987.

[15] H. Andersson and C. Persson, "In-situ SEM study of fatigue crack growth behaviour in IN718," International Journal of Fatigue, vol. 26, no. 3, pp. 211-219, 2004.

[16] Z. X. Chen, Z. G. Wang, F. H. Yuan, and S. J. Zhu, "Interfacial fracture behavior of a thermal barrier coating system under four-point bend loading," Materials Science and Engineering A, vol. 483-484, pp. 629-632, 2008.

[17] S. Kuba, Y. Kojima, and H. Suzuki, "Effect of thermal barrier coating layer on HIP treated IN738LC fatigue characteristic," Key Engineering Materials, vol. 306-308, pp. 109-114, 2006. 

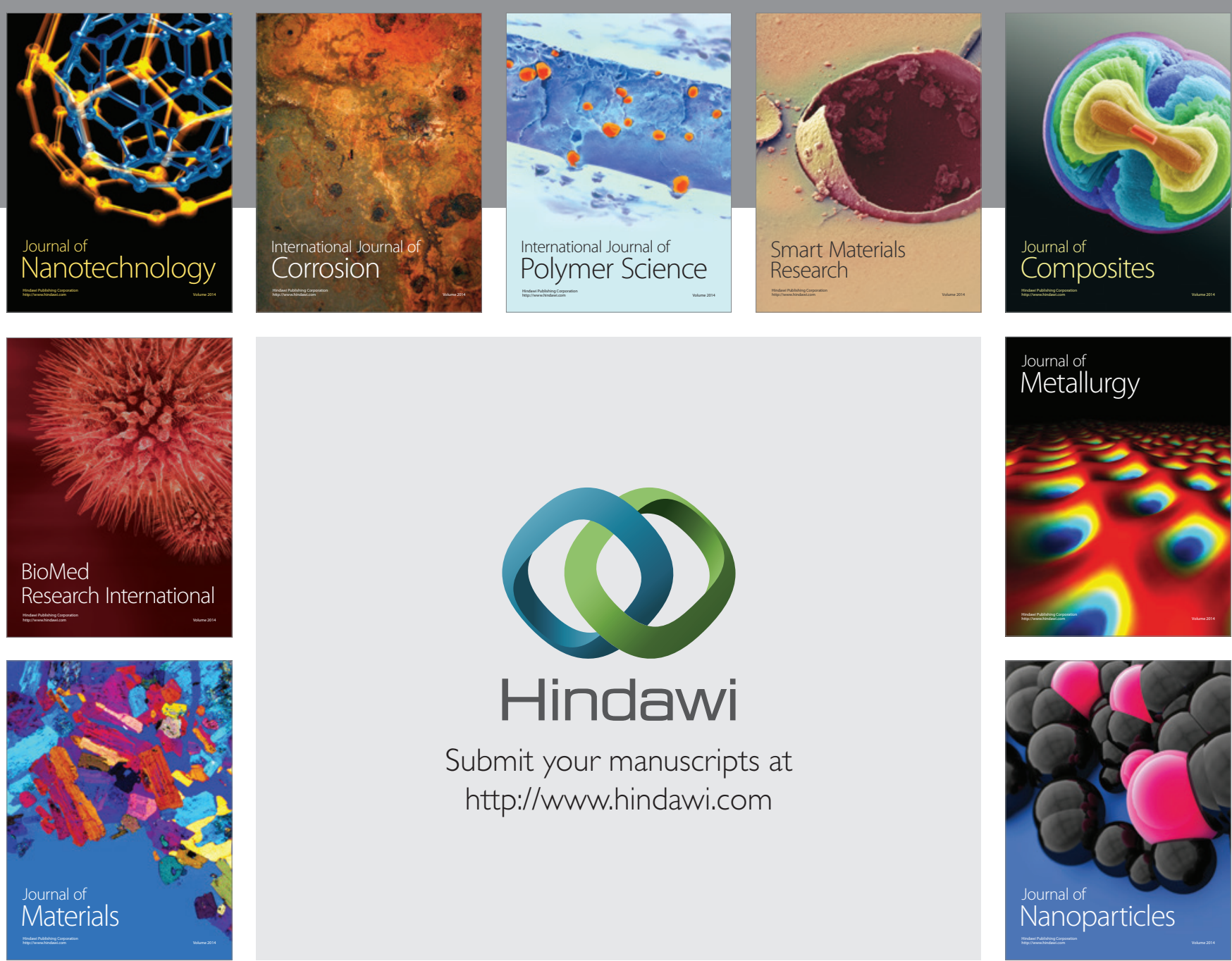

\section{Hindawi}

Submit your manuscripts at

http://www.hindawi.com

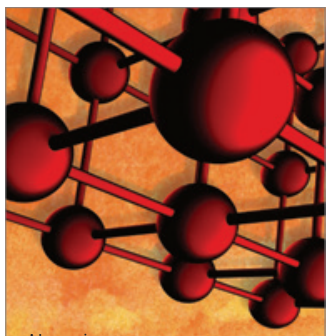

Materials Science and Engineering
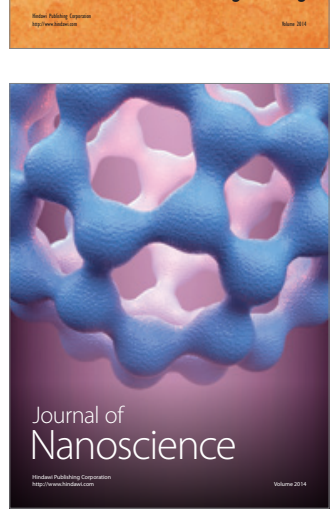
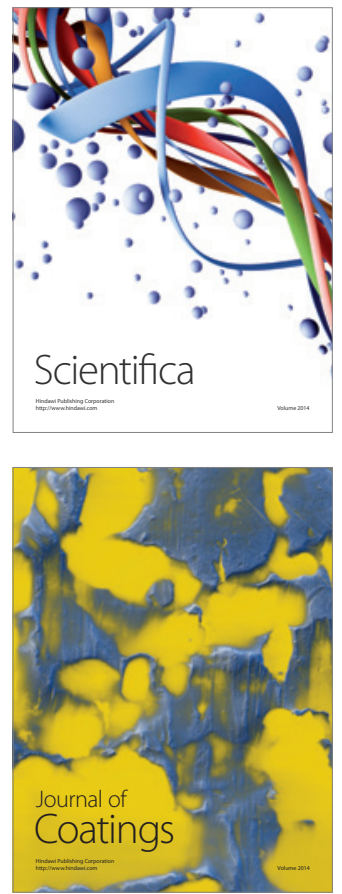
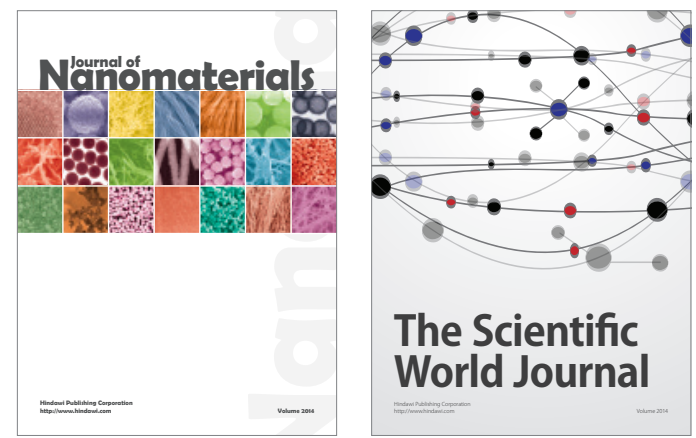

The Scientific World Journal
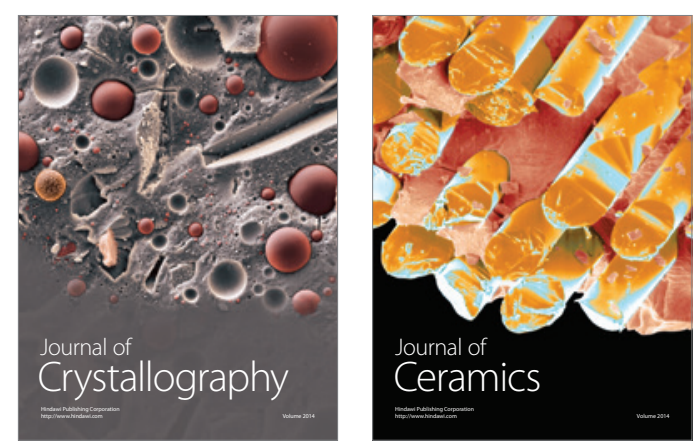
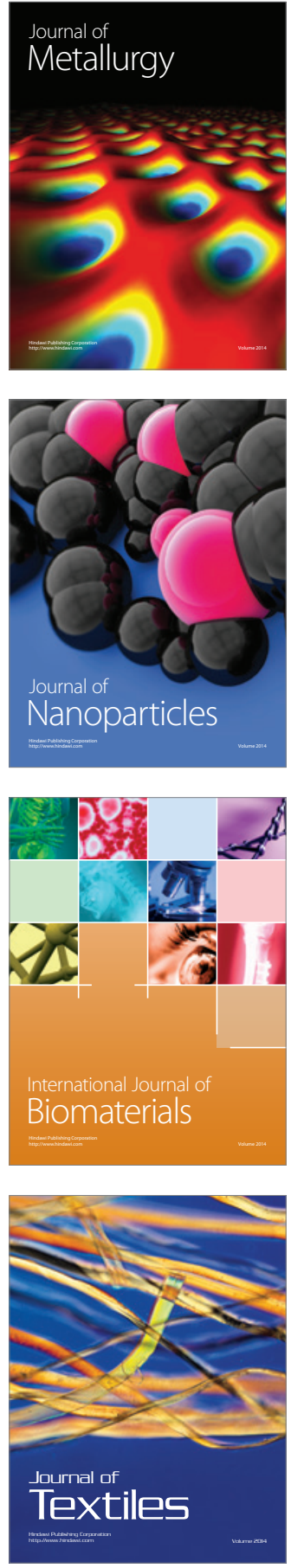